\title{
WHAT IS THE PERCEIVED VALUE OF WINE? A CROSS-GENERATION STUDY OF CONSUMER WINE PERCEPTION AND CONSUMPTION BEHAVIOR
}

\author{
Klaus-Peter Wiedmann, Leibniz University of Hannover, Germany \\ Stefan Behrens, Leibniz University of Hannover, Germany \\ Nadine Hennigs, Leibniz University of Hannover, Germany \\ Christiane Klarmann, Leibniz University of Hannover, Germany
}

\begin{abstract}
As a consequence of the highly complex nature of wine as a product, a deeper understanding of the key drivers of consumer wine perception and consumption behavior is a major challenge for practitioners and researchers in the domain of wine marketing. The desire for and the consumption of wine seems to involve several dimensions of customer perceived value perceptions. Additionally, situational determinants, consumer characteristics like product involvement, experience and needs or demographic variables such as gender and age might affect the wine purchase.
\end{abstract}

Against this backdrop, incorporating relevant theoretical and empirical findings, our study focuses on the antecedents leading to the consumption of wine in general and with particular attention to a comparison between the attitudes and behavior of wine consumers belonging to the Generation $\mathrm{X}$ and the Generation $\mathrm{Y}$. This paper is structured as follows: first, the conceptual model and related hypotheses are presented based on existing research insights on wine marketing and customer perceived value; second, the methodology and results of our empirical study are described. Third, the results of our analysis are discussed with reference to managerial implications and further research steps.

The question of what really adds value in consumer wine perception is in accordance to the insights of Wiedmann et al. (2007, 2009) defined in this paper through the existence of four latent value dimensions: the financial value of wine, the functional value of wine, the individual value of wine and the social value of wine. These four consumption values are expected to drive purchase attitude and behavior, represented in our study by the construct of wine consumption. Within this context the involvement construct describes the perceived relevance of a specific product - in our case wine - derived from inherent needs, values and interests.

To measure the dimensions of value-related consumer attitudes and behavioral effects on wine consumption focusing on Generation X and Generation Y consumers, we relied on already existing and tested measures. All items were specified to a wine consumption context and rated on five-point Likert scales $(1=$ strongly disagree to $5=$ strongly agree $)$. The questionnaire was pre-tested with 50 respondents of both consumer groups to ensure the quality of the items used against the backdrop of our conceptual model and related hypotheses. To investigate the research model, we conducted 215 personal interviews in Germany with regular wine consumers representing the Generation X and Y. In our exploratory study context of examining the drivers and outcomes of wine consumption based on a cross-generation sample, we conducted a PLS path modeling analysis with case-wise replacement and a bootstrapping procedure (individual sign changes; 215 cases and 1000 samples) to test our hypothesized structural relationships.

Referring to the whole sample, the latent variables financial value, functional value, individual value, social value and involvement reveal a positive relationship to the latent variable wine consumption. Besides, while the impact of all other customer perceived value dimensions was significant for the Generation $\mathrm{X}$ sample, for the Generation $\mathrm{Y}$ sample, no significance could be found in the positive relations of financial, functional, and social value perception to wine consumption. In contrast to this, the positive impact of the latent variable wine involvement on wine consumption is only significant for the Generation Y sample. Consequently, it can be stated that Generation X consumers put significantly more emphasis on the different perceived value aspects regarded as a whole, whereas the product-specific involvement is of particular importance especially for Genration Y consumers.

Based on insights of the types of value consumers perceive in the context of wine consumption, successful management strategies should focus on the customer's subjective expectations and individual value perceptions to be able to deliver sufficient value. By addressing the specific value aspects that are highly relevant for consumer loyalty to the product or brand, winery owners and distributors can stimulate purchase behavior with appropriate campaigns that emphasize the most important value aspects. Besides, the differences in the perceived importance of the various antecedents of wine consumption can be used to segment the wine market accordingly.

References Available Upon Request 